\section{What kind of democracy?}

\author{
Participation, Inclusiveness and Contestation \\ Kateřina Vráblíková \\ New York - London 2016: Routledge, 230 pages.
}

Miriam Haselbacher

Institut für Politikwissenschaft, Universität Wien, Österreich

E-Mail: miriam.haselbacher@univie.ac.at
The manifestations of interactions between citizens and their representatives are a decisive element in shaping and characterising political systems. How do citizens get involved in political processes and how does this civic engagement influence democracies? What ways of participation do exist besides the act of voting? And what factors may have an influence on a more or less engaged citizenry? In 'What kind of Democracy' Kateřina Vráblíková adopts a comparative perspective to address those questions and asks how political inclusiveness/ exclusiveness and public contestation/consensus influence participation. She investigates how 'individuals' national political contexts affect their engagement in nonelectoral political activism" (xiii). Comparing 30 contemporary democracies the book asks "how and why people in some countries tend (...) to participate more in nonelectoral politics than people in other countries" amid the "generally shared aspiration to have a more active citizenry" (3). Vráblíková develops a democratic model of 'inclusive contestation' that is said to facilitate nonelectoral participation, linking the three dimensions of the book's subtitle to each other. Based on those considerations it is argued that political rivalry, contestation and competition motivate people to take action. Methodologically, Vrablikova worked with the 2004 ISSP (International Social Survey Programme) and supplemented it with macrolevel factors and other nationally representative surveys.

The book is divided into eight subchapters and starts with an introductory chapter that describes what is called the 'landscape puzzle' and provides an overview to the reader about the volume. Chapter two presents the main arguments and develops an inclusive-contestation theory drawing on Robert Dahl's approach and contra- dicting traditional inclusive consensus traditions. In the following chapters ( 3 to 6) the model is tested amid the empirical evidence, with chapter 3 focusing on microlevel and chapter 4, 5, and 6 on macrolevel explanations of political participation. The latter refers to institutional structures (chapter 4), mobilization (chapter 5) and the political culture (chapter 6). Chapter 7 summarizes the empirical part and concludes that it is classical microlevel theories that explain who participates and that it is the contextual theory of inclusive contestation that explains where this participation takes place. The final and conclusive chapter (Chapter 8) is divided into two parts: it starts by going back to initial reflections on democratic theory and proceeds by pointing out the practical implications this work may have for policymaking. The formerly developed inclusive contestation model is contrasted with more traditional normative models of democracy since confrontation between conflicting interests is considered to be an essential element of inclusive democratic systems. This theory-driven discussion is enriched by practical conclusions and recommendations that are based on the principles of inclusive contestation. Linking individual, institutional and cultural factors, the book determines specific systemic arrangements to be decisive for the enhancement of public engagement. Vráblíková ends the book with the formulation of five general rules that should be followed in participatory policymaking.

As Vráblíková lays out, participatory channels have been booming, but the concrete form, variations and the extent of nonelectoral instruments remain a politically contested issue. In times of growing electoral success of right-wing populist parties more than ever. The book therefore contributes highly to current discussions 
about democracy as such, as well as the proper institutional environment to encourage the inclusion of citizens and enhancing public participation. Its strength derives from the thoughtful and elaborate combination of empirical research on political participation and the author's observations on democratic theory. The strong theoretical approach is related to the empirical data and concludes in a discussion about the implications of those findings for normative democratic theories. This fresh and ingenious approach makes it stimulating to readers who are interested in democratic theory as well as for those, who wish to gain a greater understanding of nonelectoral political participation or who wish to have a practical guide for policymaking based on the model of inclusive contestation. It provides new notions on discussions about conceptions of democracy and practical considerations about possible enforcement of nonelectoral political participation. 